\title{
The Religious, the Paranormal, and Church Attendance: A Response to Orenstein
}

\author{
Andrew McKinnon
}

--This is a draft version only - the final version appears as Andrew M. McKinnon 'The Religious, the Paranormal, and Church Attendance: A Response to Orenstein' Journal for the Scientific Study of Religion 42:2 (2003) 299-303 (http://onlinelibrary.wiley.com/doi/10.1111/1468-5906.00181/abstract)

\begin{abstract}
Orenstein's (2002) JSSR article "Religion and Paranormal Belief” "uses Reginald Bibby's 1995 Project Canada data to argue that religious and paranormal belief are positively correlated, but that church attendance and paranormal belief are negatively correlated. In this response, I use the same data to show that while his basic model is true, we also need to consider the interaction between church attendance and religious belief. Religious attendance conditions the effect of religious beliefs on paranormal beliefs in an important fashion. I find that religious and paranormal belief are positively correlated, but only for those who do not attend church regularly.
\end{abstract}

Theodore Adorno liked to tell the story of someone he interviewed while doing the research for The Authoritarian Personality (1954). This individual claimed that "he believed in Astrology because he did not believe in God" (Adorno 2001:3). This, Adorno suggests, is emblematic for the relationship between "occult" and "religious" beliefs, that the former is typically a substitute for the other.

A very interesting recent article by Alan Orenstein in JSSR (2002) uses Reginald Bibby's (1995) Project Canada data to challenge this oftmade claim; paranormal beliefs, he demonstrates, are not substitutes for religious belief. Rather, conventional and "paranormal" religious beliefs are in fact strongly and positively correlated. In this article, I will extend that research by examining what conditions the relationship between conventional and paranormal beliefs. 
Orenstein uses six questions to produce a scale of "conventional" and "unconventional" or "paranormal" beliefs (both ranging from 1 to 4). The first of these scales (conventional) includes belief in God, heaven, angels, hell, life after death, and that "you have experienced God's presence." The second scale (unconventional or paranormal belief) includes the following items: extra-sensory perception (ESP), that some people have psychic powers; that you have experienced an event before it happened; astrology; that it is possible to communicate with the dead; that you will be reincarnated. Using these scales, Orenstein has made a compelling case that conventional religious and unconventional religious beliefs are positively correlated, but that unconventional beliefs and church attendance are negatively associated, even when controlling for religious affiliation, gender, education, marital status, and having moved in the last five years (Orenstein 2002:308).

The question that emerges from Orenstein's analysis is this: If religious beliefs are positively correlated with paranormal beliefs, and church attendance is negatively correlated with paranormal belief, is it possible that church attendance conditions the relationship between religious and paranormal belief? We can hypothesize that the relationship between religious and paranormal beliefs will be different for regular attenders than for those who are not regular attenders. My analysis builds on Orenstein's basic model and seeks to extend it by looking at this relationship.

\title{
METHODS
}

\author{
TABLE 1
}

PARANORMAL BELIEFS: ORENSTEIN'S (2002:308)

RESULTS AND THE REPLICATION USING THE ORIGINAL PUBLISHED SPECIFICATIONS (STANDARDIZED COEFFICIENTS)

\begin{tabular}{lcc}
\hline Variable & Orenstein (2002) & Replication \\
\hline Conventional belief & $+0.53^{*}$ & $+0.40^{*}$ \\
Church attendance & $-0.39^{*}$ & $-0.32^{*}$ \\
"Nones" & -0.02 & +0.04 \\
Female & $+0.18^{*}$ & $+0.18^{*}$ \\
Age & $-0.07^{*}$ & $-0.09^{*}$ \\
Education & $-0.05^{*}$ & $-0.05^{*}$ \\
Divorced & $+0.05^{*}$ & $+0.06^{*}$ \\
Moved last 10 yrs & $+0.07^{*}$ & $+0.05^{*}$ \\
Adjusted R $R^{2}$ & 0.245 & 0.227 \\
\hline
\end{tabular}

In the interests of comparison, I have replicated the variables in Orenstein (2002) as closely as possible and used the same data set (Bibby 
1995). ${ }^{1}$ Like the earlier research, I have includedonly those respondents with Catholic, Protestant, and no religious affiliation (excluding all "others"); the variables have been constructed according to Orenstein's published specifications. In Table 1, I have placed his results (using standardized coefficients) next to my replication of his results, using all of the same variables, and having coded them in the manner specified in his article.

My replication of Orenstein's results shows very minor variations from the model presented in the earlier research (Orenstein 2002) resulting from the minor differences between our conventional religious beliefs scale. Using standardized coefficients, the effect of conventional belief drops from +0.53 to +0.40 , the effect of attendance changes from -0.39 to -0.32 , and the adjusted $\mathrm{R}^{2}$ is somewhat smaller ( 0.227 compared with the original 0.245). Despite the minor inconsistency in the conventional religious beliefs variable, the basic model changes only slightly, with both direction of effects and significance identical to Orenstein's model, and the strength of effects virtually identical.

In my subsequent models, I will be treating attendance somewhat differently than it has been in the previous research (Orenstein 2002). Although it is quite a common practice to treat attendance as a continuous variable, we cannot assume that the response categories are equidistant. Further, when we look at the bivariate relationship between church attendance and being high on the paranormal scale, we get the following figures (Orenstein 2002:305): 27 percent of those with low religious attendance are high on the paranormal scale, 34.6 percent of those with medium attendance are, as also are 20.6 percent of those with high attendance. This does not suggest that the relationship between religious attendance and paranormal belief is most appropriately treated as a linear one. Thus, in my analysis I have used a series of ordered categories for attendance: never attends to once a year (omitted), attends irregularly (several times a year to two to three times a month), and regularly attends (nearly every week or more). 
TABLE 2

REGRESSION MODELS INCLUDTNG ATTENDANCE BI CONVENTIONAL BELIEP INTERACTIONS

(UNSTANDARDIZED COEFFICIENTS)

\begin{tabular}{lccc}
\hline & Model 1 & Model 2 & Model 3 \\
Variable & $B$ & $B$ & $B$ \\
\hline Constant & 1.575 & 1.292 & 1.239 \\
Convent. belief & $0.350^{*}$ & $0.463^{*}$ & $0.487^{*}$ \\
Regular attend. & $-0.500^{*}$ & $0.827^{*}$ & $0.887^{*}$ \\
Irregular attend. & $-0.141^{*}$ & $-0.193^{*}$ & 0.044 \\
"Nones" & 0.014 & 0.086 & 0.098 \\
Female & $0.248^{*}$ & $0.225^{*}$ & $0.224^{*}$ \\
Age & $-0.003^{*}$ & $-0.004^{*}$ & $-0.004^{*}$ \\
Education & $-0.032^{*}$ & $-0.024^{*}$ & $-0.024^{*}$ \\
Divorced & $0.132^{*}$ & $0.125^{*}$ & $0.127^{*}$ \\
Moved last 10 yrs & $0.066^{*}$ & $0.056^{*}$ & $0.053^{*}$ \\
Reg. attend" conventional & & $-0.442^{*}$ & $-0.447^{*}$ \\
Irreg. attend* conventional & & & -0.085 \\
Adjusted $R^{2}$ & 0.256 & 0.293 & 0.294 \\
df & 9 & 10 & 11 \\
$F$ & 58.943 & 63.747 & 58.252 \\
Improvement & - & $*$ & \\
\hline
\end{tabular}

*Significant at 0.05 .

Table 2 shows three models, which, like Orenstein (2002), use OLS regression, and use the same control variables. I have presented these models using unstandardized coefficients in order to make them easier to interpret. Model 1 reproduces Orenstein's model (but using ordered categories for attendance). This is the base model, from which we will determine whether adding interaction terms for regular attendance by conventional belief and irregular attendance by conventional belief provides a model that better fits the data. In Model 2 the interaction term for conventional belief by regular attendance is added to the base model. The model is significant and shows improvement over Model 1 (significant at the 0.05 level). Model 3 adds an interaction term for irregular attendance by conventional belief. This model does not provide an improved fit over Model 2 (or even the base model). Model 2 is therefore the preferred model. 


\section{INTERPRETATION}

Although Orenstein contends that conventional belief and paranormal belief are positively correlated, Model 3 demonstrates that the effect of conventional belief differs by attendance. Setting all of the control variables to the mean, we can show this difference in Figure 1. The paranormal scale runs from 1 to 4 , where 1 indicates the lowest possible level of paranormal belief and 4 indicates the highest level of paranormal belief. The conventional belief scale operates in the same manner.

As we can see in Figure 1, there is virtually no relationship between conventional religious beliefs and paranormal beliefs for those who are regular attenders. Those with the lowest level of conventional belief (1) have an average of 1.993 on the paranormal scale. Those with the highest level of conventional belief (4) have an expected value of 2.056 on the

FIGURE 1

\section{CONVENTIONAL BY UNCONVENTIONAL BELIEF (ATTENDANCE GROUPS)*}

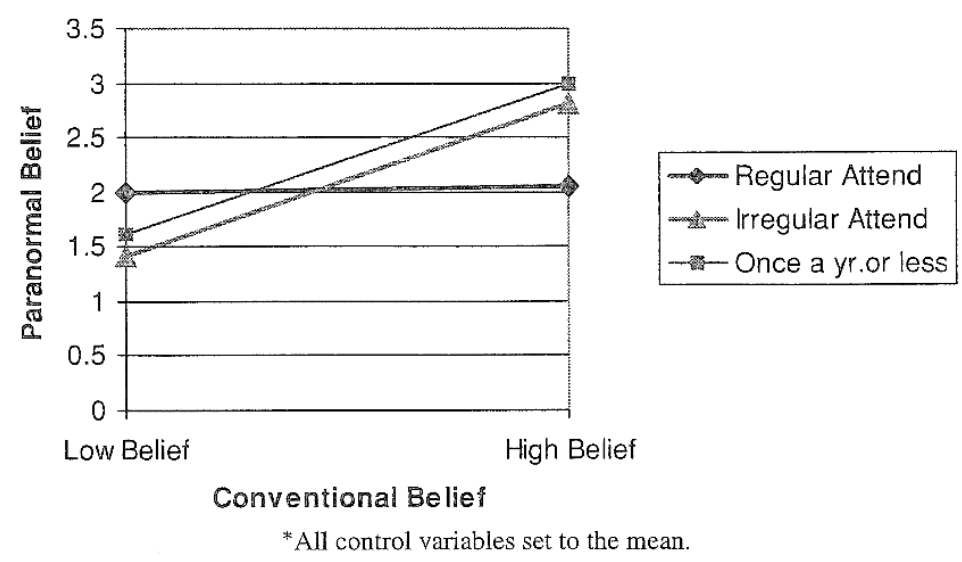

paranormal scale.

The regression line for those who attend church services only once a year or less has a significantly different slope (which runs parallel to the line for those who attend irregularly). For those who attend once a year or less, those with the lowest level of conventional belief (1) have an expected value of 1.608 on the paranormal scale. This rises sharply with an increase in conventional belief. Those who score highest on the conventional belief scale (4) have an expected value on the paranormal scale of almost 3 (2.997). The regression line for those who attend irregularly (less than "almost every week" but at least "several times a year") rises from 1.415 to 2.804 on the paranormal scale. For both of these groups, the effect of conventional religious beliefs on unconventional beliefs is substantial, especially in contrast to the "flat line" for those who are regular attenders. 


\section{DISCUSSION AND CONCLUSION}

I began this article with Theodor Adorno's anecdote about the man who believed in astrology because he did not believe in God. Orenstein has shown that paranormal belief is not a substitute for conventional religious belief because the two kinds of belief are positively correlated. Using the same survey data, I have shown that there is a significant and substantively important interaction effect. Extending his analysis, I have shown that while it is true that levels of conventional belief are positively associated with (unconventional) paranormal belief, this is really only true for those who are not actively involved in religious communities (as measured by attendance).

Orenstein's paper concludes that the "results are not compatible with a view of the paranormal as a compensatory mechanism for something missing in the lives of the irreligious" (2002:309). Given that the positive correlation between religious and paranormal beliefs is really only true of those that are not regular church attenders, this needs to be qualified. It is possible that people who are regular attenders are discouraged from believing in these kinds of "unconventional beliefs," but in this case, we would expect to see a negative relationship, and not a straight line. It seems more likely that paranormal beliefs act as a substitute for religious involvement for those who hold other conventional religious beliefs.

Orenstein is quite right to point to the increasingly individual, voluntary nature of religious belief and practice (2002:309). Reginald Bibby (1987), who gathered this data (1995), refers to the dominant Canadian religious ethos as "religion à la carte." However, the tendency to adopt "conventional" and "unconventional" beliefs together is mostly true of those who are not regular attenders. It may not seem immediately obvious that particular beliefs could substitute for a practice (church attendance). However, paranormal beliefs are part of the "lived religion" for many Canadians - a complex constellation of religious beliefs and practices for living and making sense of their lives. Paranormal beliefs and practices, as one of the various "spiritualities," seem to be the product of a society that is, to use Grace Davie's phrase, "believing without belonging" (Davie 1994). Those who maintain conventional religious beliefs but are not regular church attenders are considerably more likely to believe in a range of unconventional beliefs as well.

\section{ACKNOWLEDGMENTS}

The author would like to thank Professors Ann Sorenson and Dean Behrens for their helpful feedback on this article 


\section{NOTE}

1. In the process of generating a basic model, it was discovered that there were very slight inconsistencies between the published specifications of the conventional belief scale and the variable used in that analysis. The two variables are correlated at 0.992 (correspondence with Alan Orenstein, June 10, 2002). In my analysis, I have adhered to the published specifications. As Table 1 demonstrates, the difference between the two variables makes virtually no substantive difference to the model.

\section{REFERENCES}

Adorno, T. 2001. Metaphysics: Concepts and problems.

Stanford, CA: Stanford University Press.

Bibby, R. W. 1987. Fragmented gods: The poverty and

potential of religion in Canada. Toronto: Irwin.

1995. Project Canada data (machine readable data file). Made

available by the American Religion Data Archives.

Davie, G. 1994. Religion in Britain since 1945: Believing without belonging. Oxford/Cambridge, MA: Blackwell.

Orenstein, A. 2002. Religion and paranormal belief. Journal for the

Scientific Study of Religion 42(2):301-11. 